\title{
Preliminary Investigation of Zircaloy-4 as a Research Reactor Cladding Material
}

Brian Castle Daniel Wachs Sean Morrell

May 2012

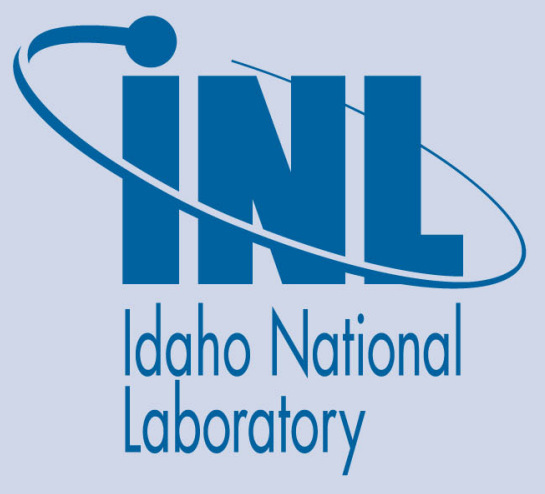

The INL is a U.S. Department of Energy National Laboratory operated by Battelle Energy Alliance 
INL/EXT-12-25814

\title{
Preliminary Investigation of Zircaloy-4 as a Research Reactor Cladding Material
}

\author{
Brian Castle \\ Daniel Wachs \\ Sean Morrell
}

May 2012

\section{Idaho National Laboratory \\ Idaho Falls, Idaho 83415}

http://www.inl.gov

\author{
Prepared for the
}

U.S. Department of Energy

Office of National Nuclear Security Administration

Under DOE Idaho Operations Office

Contract DE-AC07-05ID14517 
TEM-10300-1

$03 / 01 / 2012$

TECHNICAL EVALUATION

Page 1 of 14

Rev. 03

Title: $\quad$ Preliminary Investigation of Zircaloy-4 as a Research Reactor Cladding Material

$\begin{array}{llll}\text { TEV No.: } & 1542 \quad \text { Rev. No.: } & 0 & \text { Project No.: }\end{array}$

Date: $05 / 18 / 2012$

\begin{tabular}{|l|l|l|}
\hline 1. Quality Level (QL) No. & & \multirow{2}{*}{ Professional Engineer's Stamp } \\
\hline 2. QL Determination No. & \\
\hline 3. Engineering Job (EJ) No. & \\
\hline 4. SSC ID & \\
\cline { 1 - 2 } 5. Building & & \\
\hline 6. Site Area & & \\
\hline
\end{tabular}

7. Introduction:

As part of a scoping study for the Advanced Test Reactor (ATR) fuel conversion project, an initial comparison of the material properties of Zircaloy-4 ( $\mathrm{Zr}-4)$ and aluminum-6061 (T6 and O-temper) is performed to provide a preliminary evaluation of $\mathrm{Zr}-4$ as a candidate cladding material for ATR fuel elements. The current fuel design for the ATR uses aluminum-6061 (T6 and O-temper) as a cladding and structural material and this design is proven to have a high degree of reliability.

Because of the successful and longstanding operating history of aluminum-6061 (Al-6061) cladding in the ATR, Zr-4 properties will be evaluated against Al-6061 material properties. The preliminary investigation will focus on a comparison of densities, oxidation rates, water chemistry requirements, mechanical properties, thermal properties, and neutronic properties.

8. Revision 0

9. Conclusions/Recommendations:

In the event that aluminum becomes a nonviable option for the ATR fuel cladding, a more detailed analysis of the resulting thermal and structural changes, associated with a change in fuel cladding, should be performed. This assertion is predominantly based on the following:

- $\quad$ The thermal conductivity of Zr-4 is significantly lower than Al-6061, which may necessitate operating the fuel at a higher centerline temperature and may result in non-beneficial changes to the operating parameters of the reactor.

- $\quad$ Replacing the Al-6061 cladding with $\mathrm{Zr}-4$ would increase the weight of the core by approximately $265.6 \mathrm{~kg}$ in addition to any increase from the fuel. 
TEM-10300-1

Rev. 03

Title: $\quad$ Preliminary Investigation of Zircaloy-4 as a Research Reactor Cladding Material

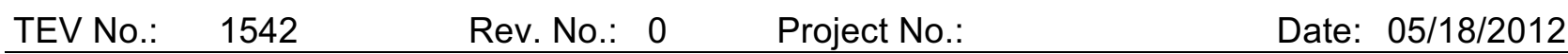

\section{CONTENTS}

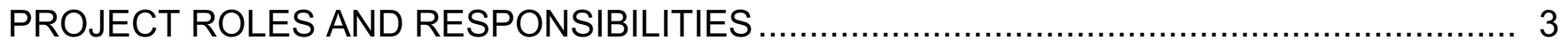

INTRODUCTION

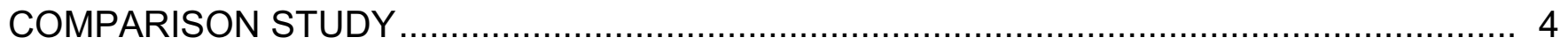

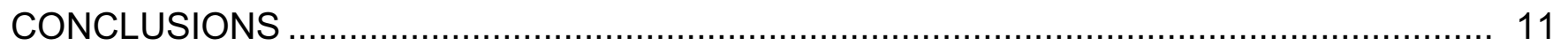

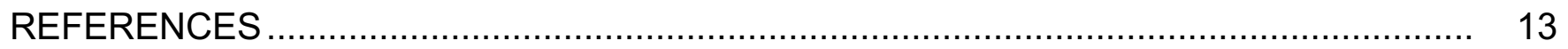


TEM-10300-1

$03 / 01 / 2012$

TECHNICAL EVALUATION

Page 3 of 14

Rev. 03

Title: $\quad$ Preliminary Investigation of Zircaloy-4 as a Research Reactor Cladding Material

TEV No.: $1542 \quad$ Rev. No.: 0 Project No.:

Date: $05 / 18 / 2012$

\section{PROJECT ROLES AND RESPONSIBILITIES}

\begin{tabular}{l|l|l|l}
\multicolumn{1}{c|}{ Project Role } & Name (Typed) & Organization & Pages Covered (if applicable) \\
\hline $\begin{array}{l}\text { Performer } \\
\begin{array}{l}\text { Checker } \\
\text { Independent Reviewer }\end{array}\end{array}$ & $\begin{array}{l}\text { Brian Castle } \\
\text { Dan Wachs }\end{array}$ & & \\
$\begin{array}{l}\text { CUl Reviewer } \\
\text { Manager }\end{array}$ & & & \\
$\begin{array}{l}\text { Requestor } \\
\text { Nuclear Safety }\end{array}$ & Sean Morrell \\
Document Owner & Sean Morrell & & \\
Responsibilities & &
\end{tabular}
a. Confirmation of completeness, mathematical accuracy, and correctness of data and appropriateness of assumptions.
b. Concurrence of method or approach. See definition, LWP-10106.
c. Concurrence with the document's markings in accordance with LWP-11202.
d. Concurrence of procedure compliance. Concurrence with method/approach and conclusion.
e. Concurrence with the document's assumptions and input information. See definition of acceptance, LWP-10200.

NOTE: $\quad$ Delete or mark "N/A" for project roles not engaged. Include ALL personnel and their roles listed above in the Electronic Change Request (eCR) system. The list of the roles above is not all inclusive. If needed, the list can be extended or reduced. 
TEM-10300-1

$03 / 01 / 2012$

TECHNICAL EVALUATION

Page 4 of 14

Rev. 03

Title:

Preliminary Investigation of Zircaloy-4 as a Research Reactor Cladding Material

$\begin{array}{llll}\text { TEV No.: } 1542 \quad \text { Rev. No.: } & 0 & \text { Project No.: }\end{array}$

Date: $05 / 18 / 2012$

\section{INTRODUCTION}

As part of a scoping study for the Advanced Test Reactor (ATR) fuel conversion project, an initial comparison of the material properties of $\mathrm{Zr}-4$ and Al-6061 (T6 and O-temper) is performed to provide a preliminary evaluation of $\mathrm{Zr}-4$ as a candidate cladding material for ATR fuel elements. The current fuel design for the ATR uses Al-6061 (T6 and O-temper) as a cladding and structural material and this design is proven to have a high degree of reliability. Because of the successful and longstanding operating history of Al-6061 cladding in the ATR, Zr-4 properties will be evaluated against Al-6061 material properties. The preliminary investigation will focus on a comparison of densities, oxidation rates, water chemistry requirements, and mechanical, thermal, and neutronic properties.

\section{COMPARISON STUDY}

\section{Aluminum-6061 and Zircaloy-4 Densities}

A significant core mass increase will occur if the cladding material in all 40 ATR fuel elements is replaced with $\mathrm{Zr}-4$. The ATR fuel element was estimated to have a volume of $2,829 \mathrm{~cm}^{3}$ in ECAR1006, which includes two side plates, upper and lower box, two combs, and 19 fuel plates. The side plates and combs are Al-6061 T6 and have a density of $2.715 \mathrm{~g} / \mathrm{cm}^{3}$. The fuel plate cladding is Al-6061 $\mathrm{O}$, which is assumed to have the same density as the side plates. The upper and lower box castings are aluminum-356 alloy with a density of $2.685 \mathrm{~kg} / \mathrm{cm}^{3}{ }^{6,7}$ In ECAR-1006, the volume of cladding material in the ATR fuel was determined, but fuel plate 19 was assumed to contain no fuel and was a solid plate of Al-6061. For this current study, the cladding volume calculations in ECAR-1006 are used with a correction for the cladding volume of fuel plate 19 , recalculated to reflect the geometry of an actual ATR fuel element.

Based on ECAR-1006, the total volume of the Al-6061 fuel cladding plates for an ATR fuel element is $1,673.8 \mathrm{~cm}^{3}$. If the entire fuel element were made of $\mathrm{Zr}-4$ with a density of $6.56 \mathrm{~g} / \mathrm{cm}^{3}$, the mass of the cladding for an ATR fuel element would be $18.56 \mathrm{~kg}$. Replacing just the fuel cladding (not including side plates and other support material) with $\mathrm{Zr}-4$ would increase the mass of the fuel core (40 elements) by $257.4 \mathrm{~kg}$. The entire cladding and support structure of an ATR fuel element has a volume of 2,829 $\mathrm{cm}^{3}$, which includes two side plates, upper and lower box, two combs, and 19 hollow fuel plates, without fuel. If this total volume of cladding were replaced with $\mathrm{Zr}-4$, the resulting mass increase of the core would be $434.5 \mathrm{~kg}$, in addition to the mass increase due to a change in fuel composition.

There is an ongoing seismic analysis to evaluate the influences of adding weight to the core. These results will determine the appropriateness of considering $\mathrm{Zr}-4$ as a viable cladding option, based purely on the additional weight that would be added to the core.

\section{Aluminum-6061 and Zircaloy-4 Oxidation Rates}

The ATR has limits in on the maximum allowable hydroxide thickness for cladding, which is based on heat transfer concerns. The hydroxide layer of Al-6061 has a thermal conductivity of $2.2 \mathrm{~W} / \mathrm{m} \mathrm{K}$, which is relatively temperature independent. ${ }^{5}$ This hydroxide layer is less thermally conductive than the base metal, which can increase the thermal resistance of the fuel to unacceptable limits, if the hydroxide scale becomes too thick. The hydroxide also has significantly different thermal expansion characteristics than Al metal which may cause it to crack or spall off the surface when critical thicknesses are reached. The ATR staff performed a study that measured the hydroxide layers on a wide variety of irradiated fuel. It was determined that the average hydroxide thickness was $10.6 \mu \mathrm{m}$, 
TEM-10300-1

$03 / 01 / 2012$

Rev. 03

Title: Preliminary Investigation of Zircaloy-4 as a Research Reactor Cladding Material

$\begin{array}{llll}\text { TEV No.: } 1542 \quad \text { Rev. No.: } & 0 & \text { Project No.: }\end{array}$

Date: $05 / 18 / 2012$

with a maximum-recorded hydroxide thickness of $29.9 \mu \mathrm{m} .{ }^{4}$ Based on 175 operating cycles, the maximum allowable hydroxide thickness for ATR fuel cladding is specified as $25.4 \mu \mathrm{m}$. The operating cycles for the ATR are typically short, on the order of 2-8 weeks, between refueling. The normal fuel element life is 45 effective full-power days, which corresponds to a fuel burnup limit of $2.3 \times 10^{21}$ fissions $/ \mathrm{cm}^{3}{ }^{5}$ The burnup limit is in place to ensure that the fuel is operated within the demonstrated and qualified envelop and, thus, unacceptable levels of fuel plate swelling do not occur. ${ }^{4,5}$

To control hydroxide growth rates and ensure that thickness does not exceed specified limits used in thermal analyses, a pre-film of boehmite is applied to the aluminum cladding surface and the reactor coolant is maintained within a pH of 5.0-5.4. The initial deposition of boehmite passivates the fuel cladding surface and minimizes hydroxide growth during irradiation. The uniformity of the hydroxide layer and established maximum growth rate provide the important heat transfer considerations to ensure predictable heat removal.

Temperature is an important factor that influences hydroxide behavior. The local heat generation rate of the fuel and the overall thermal resistance of the cladding determine the cladding temperature. The hydroxide is formed by water autoclaving the fuel plates in a $\mathrm{pH}$ regime to grow the hydroxide layer at $180^{\circ} \mathrm{C}$. Additional hydroxide growth is expected above $180^{\circ} \mathrm{C}$ and runaway oxidation is expected above $230^{\circ} \mathrm{C}$. The ATR fuel cladding has a peak surface temperature of $181^{\circ} \mathrm{C}$ and the fuel meat reaches a peak temperature of $253^{\circ} \mathrm{C}$, with enveloping $70-\mathrm{MW}$ lobe and three pumps operating. The normal operating parameters for the ATR are an inlet temperature of $51^{\circ} \mathrm{C}$ and pressure of $2.6 \mathrm{MPa}$.

The oxidation rate of the ATR fuel is determined by the operating environment of the ATR, which includes low $\mathrm{pH}$ coolant, high neutron fluences, and low operating temperature. Performing a comparison of oxidation rates between Al-6061 and $\mathrm{Zr}-4$ is difficult due to the limited data available on $\mathrm{Zr}-4$ at these conditions. Of specific interest are the low operating temperature and low $\mathrm{pH}$ of the coolant. Typical $\mathrm{Zr}-4$ usage is in PWR reactors where the fuel operates for $\sim 1500$ effective full power days and is physically in the fuel core for about 4.6 years, so the cladding sees about 4.1 years exposure to high pressure water over $300^{\circ} \mathrm{C}$ and about 0.5 year in water closer to ATR temperatures.

Zirconium spontaneously forms an oxide layer in water or air at room temperature or below which is self healing and protects the base metal from further attack in most mineral and organic acids, and alkaline solutions unless halides are present. However, even in $20 \%$ hydrochloric acid, Zirconium alloys outperform austenitic stainless steels by several orders of magnitude ${ }^{21}$. A study was identified that measured $\mathrm{Zr}-4$ oxide thickness at $360^{\circ} \mathrm{C}$ in pure water (assumed $\mathrm{pH} 7$ ) in an unirradiated environment. The oxide layer on the $\mathrm{Zr}-4$ specimen, in pure water, accumulated a thickness of $1.5 \mu \mathrm{m}$ after 30 days and $5.9 \mu \mathrm{m}$ after 200 days. $^{3}$

Additional influencing parameters may need to be considered to fully assess the expected behavior of $\mathrm{Zr}$-4 cladding in the ATR environment, but oxide corrosion issues with $\mathrm{Zr}-4$ are highly unlikely for the short lifetime and moderate conditions involved in the ATR reactor. 
TEM-10300-1

$03 / 01 / 2012$

TECHNICAL EVALUATION

Page 6 of 14

Rev. 03

Title:

Preliminary Investigation of Zircaloy-4 as a Research Reactor Cladding Material

$\begin{array}{llll}\text { TEV No.: } & 1542 \quad \text { Rev. No.: } & 0 & \text { Project No.: }\end{array}$

Date: $05 / 18 / 2012$

\section{Water Chemistry}

The coolant chemistry guidelines for the ATR are used to assess the compatibility of Zr-4 with the ATR water chemistry. Due to the exceptional corrosion resistance of $\mathrm{Zr}-4$ oxide, only two possible degradation mechanisms have been identified for this preliminary assessment: $\mathrm{pH}$ levels, and particle deposition on the cladding surface. The water chemistry in the ATR is specifically tailored to minimize oxide formation and pitting on the aluminum cladding. The $\mathrm{pH}$ levels of the ATR are operated in the range 5.0 to 5.4 , and $\mathrm{pH}$ levels below 4.9 are not allowed due to the potential for dissolution of boehmite. The conductivity of the primary coolant water is maintained between 4 and 5 umhos. ${ }^{12}$ Iron, aluminum, and chlorine are maintained to less than $0.1 \mathrm{ppm}$. Solid particles greater than 20 microns in diameter are filtered to reach impurity levels, at or below $1 \mathrm{ppm}$ and solid particles $0.45-20$ microns in diameter are maintained at or below concentration of $0.1 \mathrm{ppm} .{ }^{5}$ The water coolant chemistry and the aluminum cladding are reasonably compatible, but general corrosion and pitting corrosion have been observed in ATR fuel. The pits in cladding are elongated in the direction of water flow. ${ }^{13}$ Corrosion of ATR fuel is mainly a function of burnup and most cladding degradation occurs during operation. Prefilming the fuel cladding with boehmite prior to use in the reactor establishes a hermetic hydroxide film which remains passive and minimizes corrosion of cladding during irradiation. Hydroxides formed under irradiation generally do not passivate and continue to grow.

Little data exists on low temperature and low $\mathrm{pH}$ operation of $\mathrm{Zr}-4$ cladding; but what is known indicates that Zr-4 should offer exceptional stability in the ATR environment. Electric Power Research Institute (EPRI) has published guidelines for the use of Zr-4 in PWRs and their recommendations indicate that low $\mathrm{pH}$ operation could result in increased surface deposition on $\mathrm{Zr}-4$ cladding. Excessive buildup of crud on the cladding exterior reduces heat transfer, which can be responsible for premature cladding failures in LWRs. EPRI has defined a standard $\mathrm{pH}$ range of operation for $\mathrm{Zr}-4$, as $\mathrm{pH}$ 6.9-7.4. EPRI states that $\mathrm{pH}$ levels below 6.9 are undesirable for $\mathrm{Zr}-4$ because they are expected to lead to greater levels of surface deposits. EPRl's recommendations are taken into consideration in this preliminary assessment; however, their recommendations are directly applicable to power reactor operation, which is considerably different from the operating environment of the ATR which has exceptionally clean primary water at considerably lower temperature. The reasons behind EPRI's guidelines were also not clearly defined, which leaves room for interpretation. In power reactors operating at temperatures above $300^{\circ} \mathrm{C}$, the water chemistry control is used to minimize the corrosion of many reactor components of varying materials, most of which have higher solubility at lower pH levels, producing more particulate matter in the coolant, leading to greater particle deposition on the cladding. The ATR water chemistry limits have been operated at various $\mathrm{pH}$ levels, but the current water chemistry has proven to be ideal for reducing corrosion of various internal components. ${ }^{13}$ While the current water chemistry is designed to limit the corrosion of the aluminum clad fuel, it has been determined to reduce corrosion of internal components of the reactor, especially the aluminum components, making it undesirable to change.

$\mathrm{Zr}-4$ oxide is insoluble in water above a $\mathrm{pH}$ of $\sim 2.0$ at room temperature, indicating low temperature and low $\mathrm{pH}$ stability. ${ }^{14}$ Like aluminum hydroxide behavior, irradiation increases the zirconium corrosion rate through the creation of free radicals at the fuel cladding surface which are highly mobile and highly reactive $^{22}$. Irradiation also increases the diffusion through the oxide layer to allow oxide growth. Like aluminum boehmite autoclaving, $\mathrm{ZrO}_{2}$ may be applied prior to irradiation using an autoclave process to provide the most hermetic, protective oxide for irradiation. However, most PWR fuel vendors have discontinued the practice as being unnecessary to achieve adequate fuel cladding performance. The 
TEM-10300-1

$03 / 01 / 2012$

TECHNICAL EVALUATION

Page 7 of 14

Rev. 03

Title:

Preliminary Investigation of Zircaloy-4 as a Research Reactor Cladding Material

TEV No.: $1542 \quad$ Rev. No.: $0 \quad$ Project No.:

Date: $05 / 18 / 2012$

assessed stability of $\mathrm{Zr}-4$ is consistent with many references in the literature, which indicate that spent LWR fuel with Zircaloy cladding are especially well suited for long-term wet storage, up to 50 years. ${ }^{16}$ There are reports of spent fuel being maintained in highly corrosive wet storage pools for extended periods of time with negligible impact on fission gas retention. ${ }^{16}$ The consideration of the wet storage environments is relevant because the $\mathrm{Zr}$-4 cladding maintained in these wet storage environments are degraded due to ever increasing neutron flux, high-temperature operation, and aggressive water chemistry in the reactor. Additionally, the length of time that some $\mathrm{Zr}$-4 claddings have spent in these pools without degradation indicates long-term chemical stability. Additionally, reprocessing of LWR fuel is complicated by the corrosion resistance of Zircaloy cladding, even after being submerged in a SNF dissolver containing moderate strength nitric acid, the fuel cladding "will emerge from the dissolver unchanged." ${ }^{20}$ Although a more detailed analysis could be performed, it is doubtful that changes in $\mathrm{ZrO}_{2}$ behavior would even be measurable at ATR water chemistry conditions.

\section{Aluminum-6061 and Zircaloy-4 Mechanical Properties}

Al-6061 has been evaluated in several ATR studies and it has been determined to have adequate mechanical properties to provide long-term safe operation. ${ }^{8,17,19}$ The mechanical properties of Al-6061 and $\mathrm{Zr}-4$ are compared to determine if there are significant differences in strength and elasticity that would indicate a clear incompatibility of $\mathrm{Zr}-4$ being the fuel cladding for the ATR. The yield strength, tensile strength, and the modulus of elasticity (Figures 1-3) of Zr-4 are greater than Al-6061, especially for fuel cladding in the fully annealed condition. This initially indicates that $\mathrm{Zr}-4$ has adequate mechanical properties for consideration as a candidate cladding material. Several studies have been performed to ascertain the structural integrity of the current 7F ATR fuel elements. Results indicate that fuel plate instability is not expected to occur in current fuel elements, even during extreme transient events. ${ }^{8}$ For a proper determination of the viability of an alternative cladding material, similar simulations need to be run for candidate cladding materials. Based on the availability of existing ABACUS models of ATR fuel elements, it is expected that a performance evaluation of different cladding materials can be completed without the allocation of significant resources.

The hexagonal close-packed (HCP) structure of Zr-4 at ATR conditions is a characteristic that may impact its use as a replacement cladding material. PWR fuel cladding is fabricated by a special pilgering process to randomize the crystallographic texture of the alloy and achieve near isotropic mechanical and thermal behavior for round fuel pin tubing. Similar randomization of the $\mathrm{Zr}-4$ fuel plate cladding structure will be necessary through controlled forming and annealing of starting plate stock and a fuel plate rolling schedule designed to minimize anisotropic behavior in service. 
TEM-10300-1

$03 / 01 / 2012$

TECHNICAL EVALUATION

Page 8 of 14

Rev. 03

Title: $\quad$ Preliminary Investigation of Zircaloy-4 as a Research Reactor Cladding Material

\begin{tabular}{llll} 
TEV No.: & $1542 \quad$ Rev. No.: & 0 & Project No.: \\
\hline
\end{tabular}

Date: $05 / 18 / 2012$

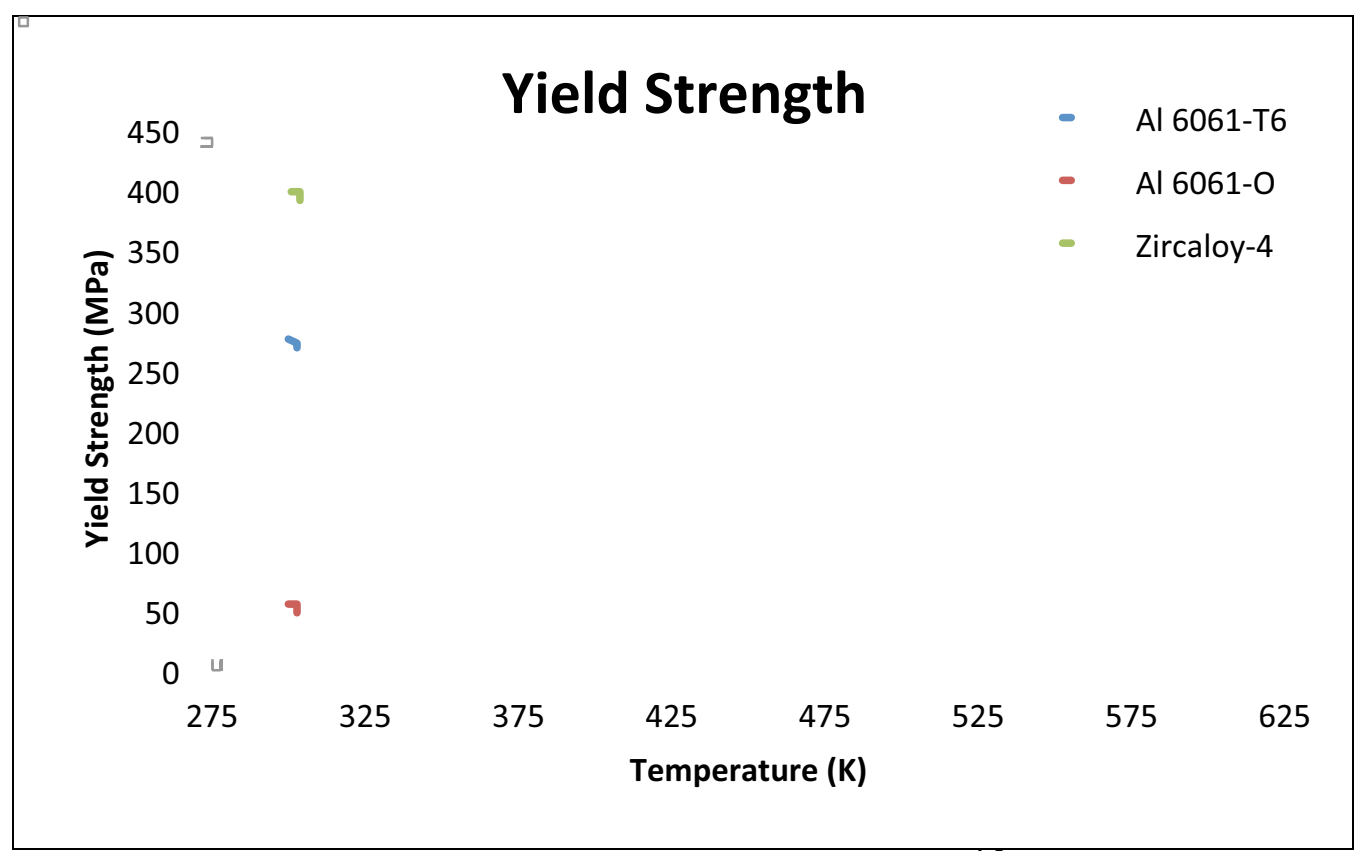

Figure 1. Yield strength comparison of Al-6061 and Zr-4. ${ }^{1,2}$

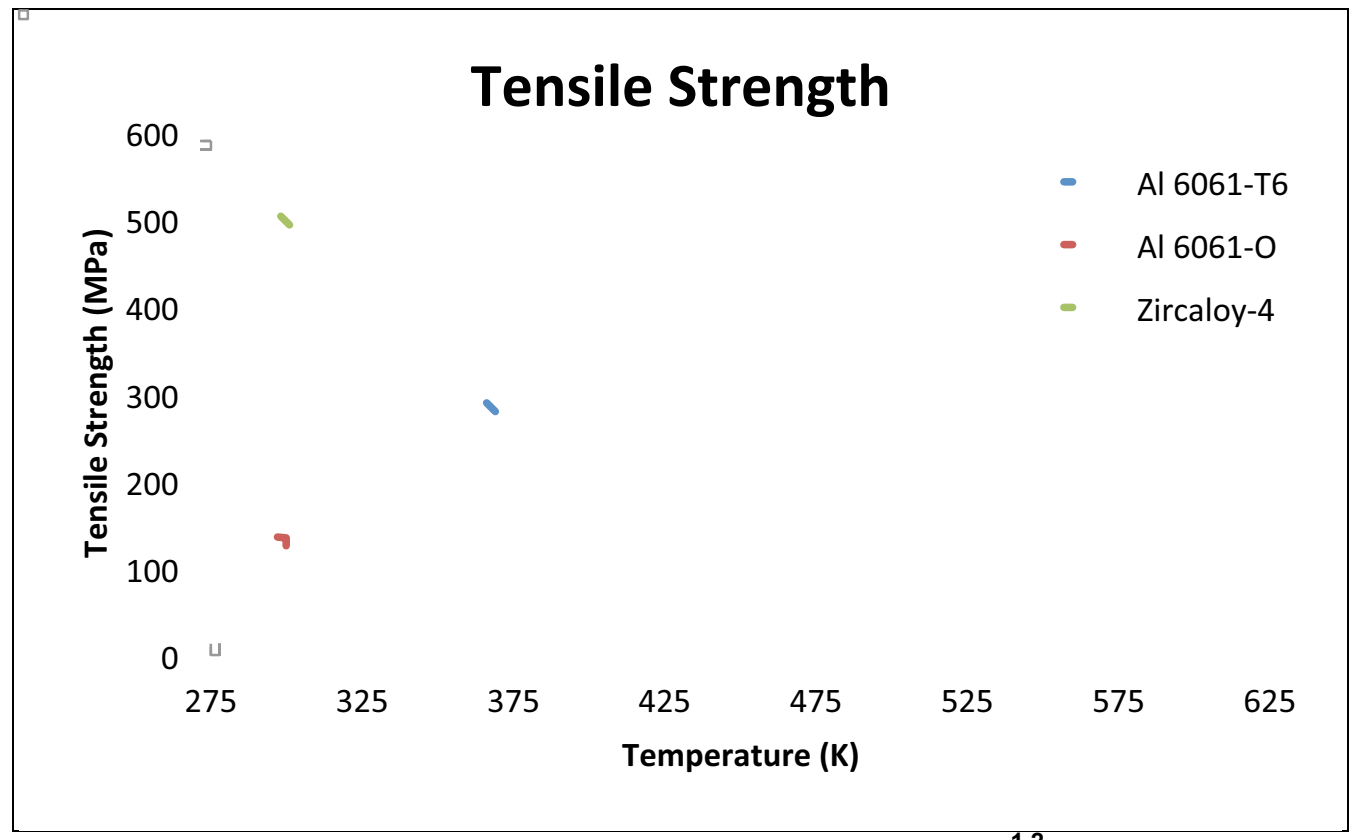

Figure 2. Tensile strength comparison of Al-6061 and Zr-4. ${ }^{1,2}$ 
TEM-10300-1

$03 / 01 / 2012$

TECHNICAL EVALUATION

Page 9 of 14

Rev. 03

Title: $\quad$ Preliminary Investigation of Zircaloy-4 as a Research Reactor Cladding Material

$\begin{array}{lllll}\text { TEV No.: } & 1542 & \text { Rev. No.: } & 0 & \text { Project No.: }\end{array}$

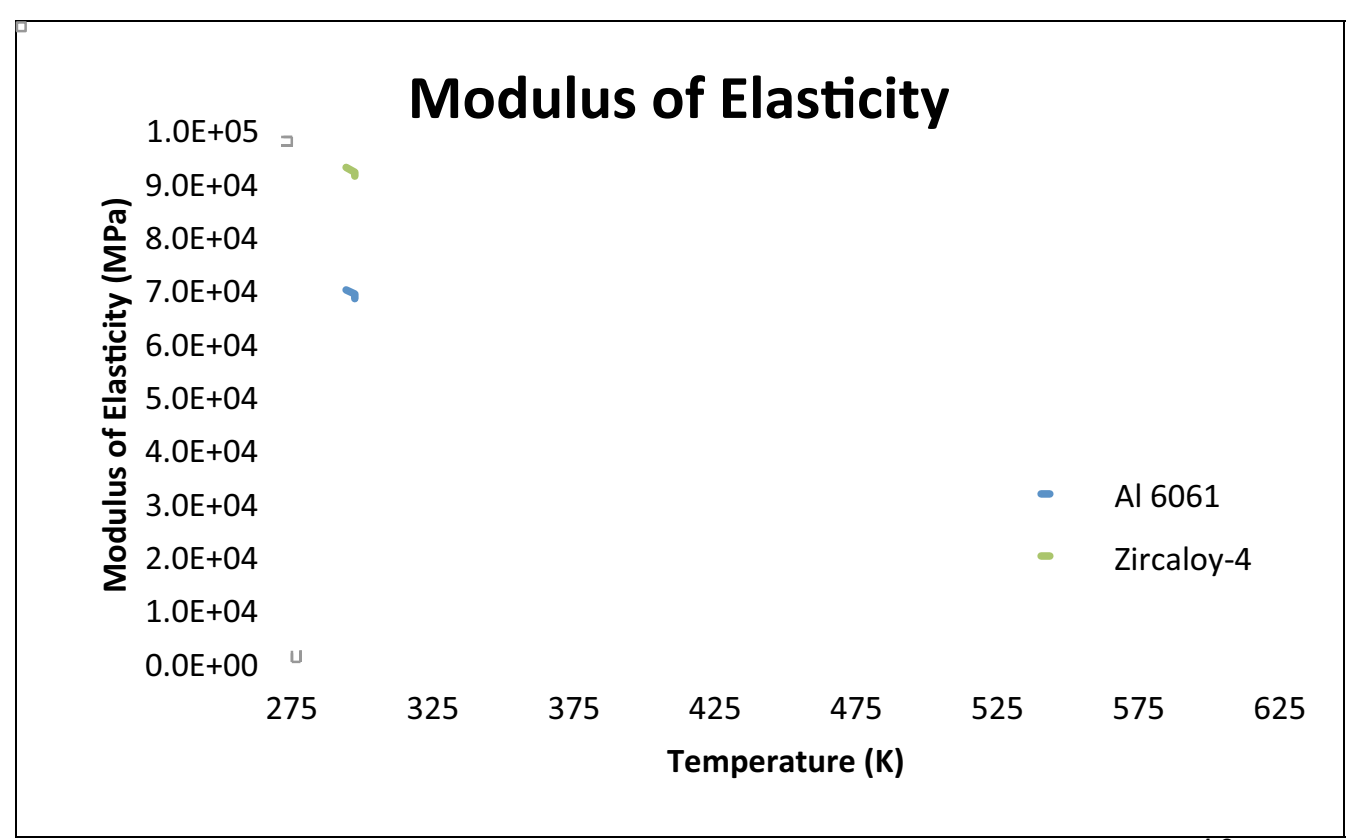

Figure 3. Comparison of the modulus of elasticity of Al-6061 and $\mathrm{Zr}-4 .^{1,2}$

\section{Aluminum-6061 and Zircaloy-4 Thermal Properties}

The heat transfer properties of nuclear fuel cladding and the inevitable oxide layer plays a significant role in establishing operating parameters such as coolant pressure, flow velocities of coolants, fuel temperature, and reactivity. Al-6061 has a very high thermal conductivity and specific heat capacity, which is a common attribute of fuel cladding in research reactors. The thermal conductivity of $\mathrm{Zr}-4$ is considerably lower than Al-6061, which is evident in Figures 4 and 5 . The thermal conductivity of the fuel cladding influences the fuel centerline temperature of the fuel. If a cladding material of lower thermal resistance were used in the ATR, significant changes would be required to re-establish adequate heat removal from the fuel or the fuel would need to operate at a higher temperature. The current velocity of the coolant across the fuel plates is between $12.3 \mathrm{~m} / \mathrm{s}$ and $14 \mathrm{~m} / \mathrm{s}$ and coupled with the high thermal conductivity of the aluminum cladding, there is significant heat removal from the fuel matrix. Even modest changes in the thermal conductivity of the cladding can have significant impacts on fuel temperatures, which can directly impact reactivity. Increased fuel temperature increases the Doppler broadening of the absorption cross section of the fuel, which results in a reduction in the effective multiplication factor. Currently, in the ATR, the oxide thickness is controlled to prevent an increase in thermal resistivity of the fuel.

Based on the implications of Figures 4 and 5, considerable heat transfer analysis would need to be completed to determine if the ATR has the capacity to operate with such a dramatically lower thermal conductivity, transitioning from Al-6061 to Zr-4. Additionally, the thermal conductivity of the oxide layer for Zr-4 needs to be evaluated to fully assess the heat transfer capabilities of Zr-4 cladding for ATR fuel. The heat transfer capacities of the cladding are a function of the oxide layer, cladding conductances, fuel meat conductances, hydraulic conditions, and power generation. 
Rev. 03

Title: $\quad$ Preliminary Investigation of Zircaloy-4 as a Research Reactor Cladding Material

\begin{tabular}{llll} 
TEV No.: & $1542 \quad$ Rev. No.: & 0 & Project No.: \\
\hline
\end{tabular}

Date: $05 / 18 / 2012$

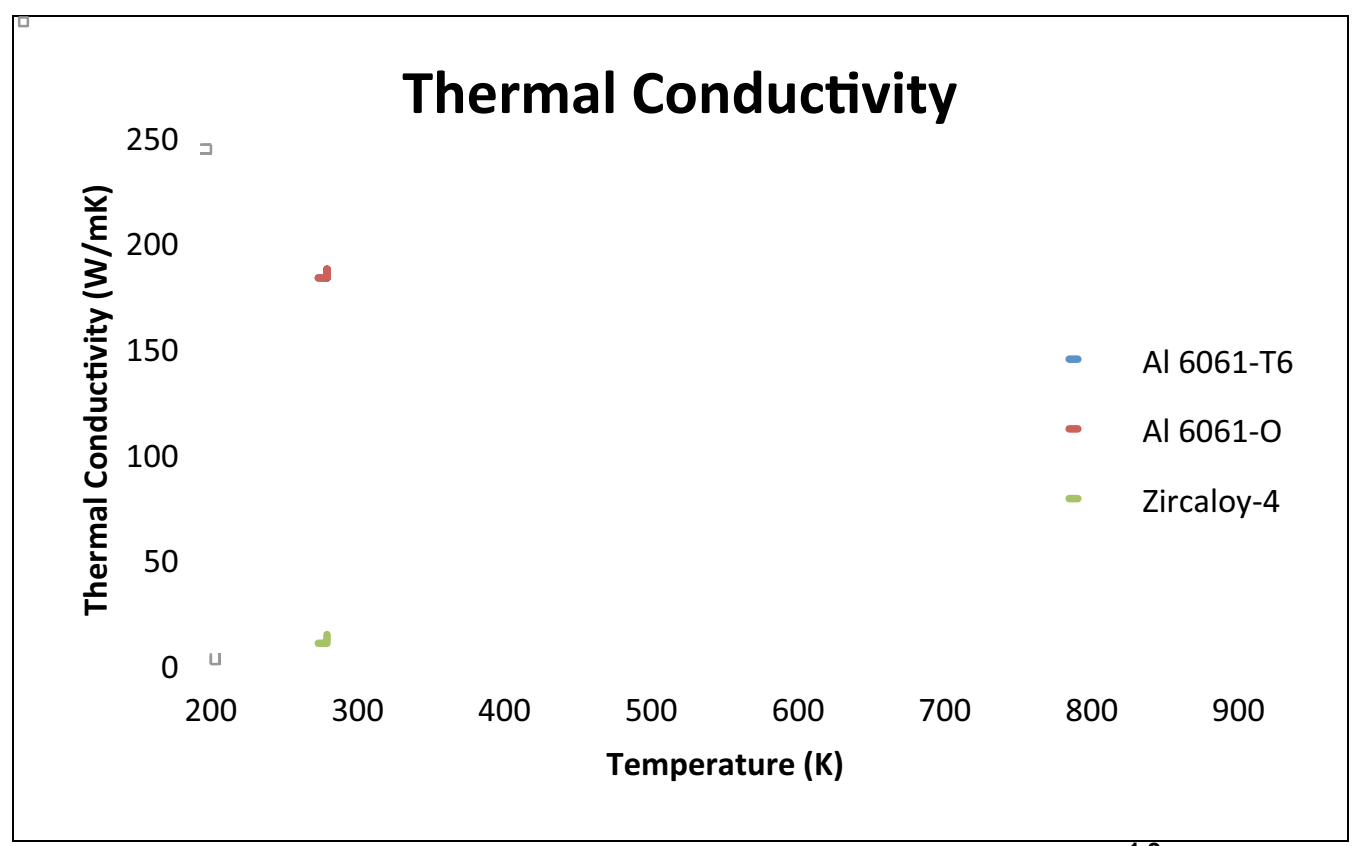

Figure 4. Comparison of thermal conductivity of Al-6061 and Zr-4.,

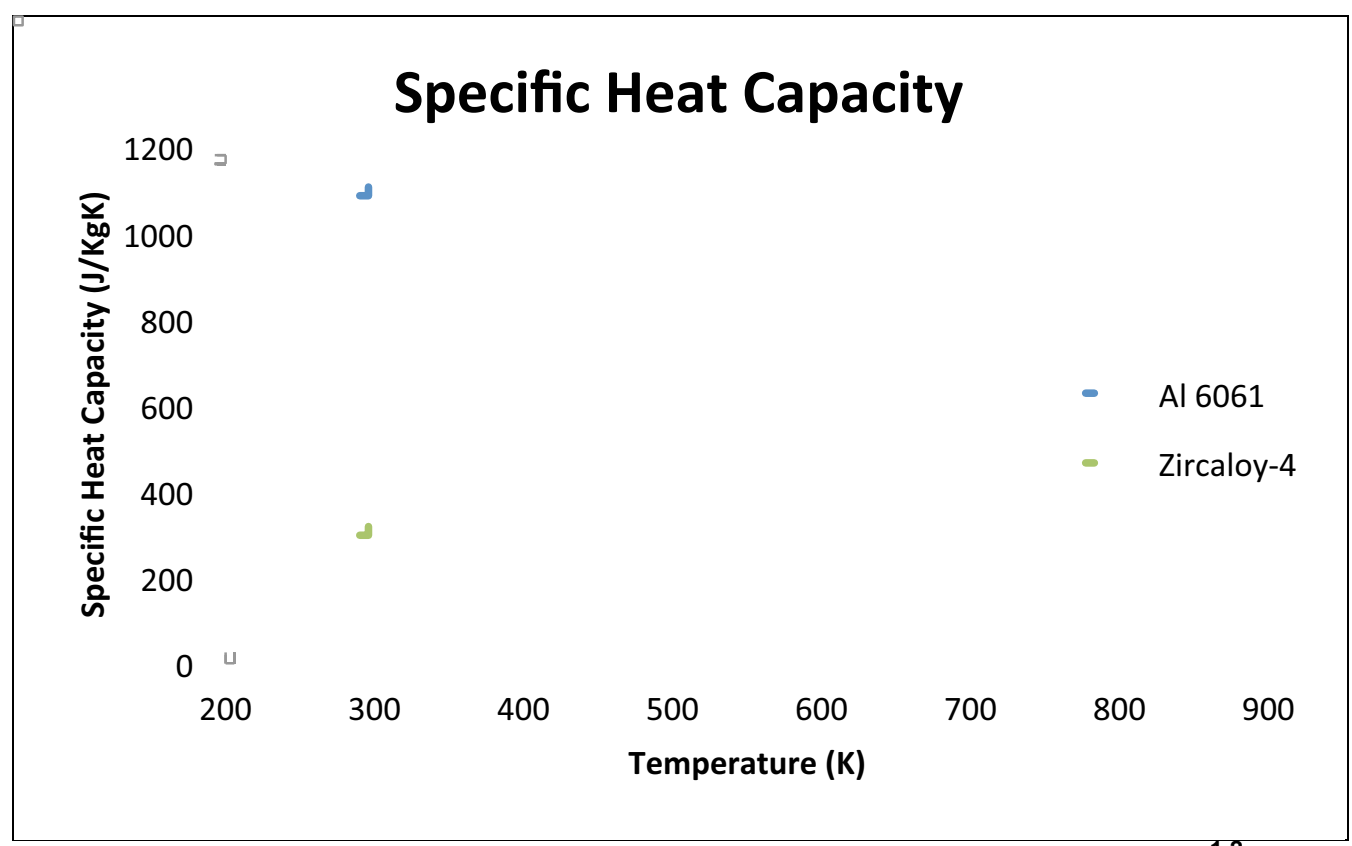

Figure 5. Comparison of the specific heat capacity of Al-6061 and Zr-4. ${ }^{1,2}$

\section{Neutronics Analysis of Aluminum-6061 and Zircaloy-4 Cladding}

The neutronic properties of both $\mathrm{Al}-6061$ and $\mathrm{Zr}-4$ are compared and performance trends are generalized and inferences are made on the effects these trends could have on the ATR. Al-6061 and Zr-4 are alloys and the major constituents of each include aluminum and zirconium, respectively. In 
TEM-10300-1

$03 / 01 / 2012$

TECHNICAL EVALUATION

Page 11 of 14

Rev. 03

Title:

Preliminary Investigation of Zircaloy-4 as a Research Reactor Cladding Material

TEV No.: $1542 \quad$ Rev. No.: $0 \quad$ Project No.:

Date: $05 / 18 / 2012$

Table 1, the neutronic properties relevant to this discussion are provided for both aluminum and zirconium.

Table 1. Cross section information for aluminum and Zirconium metals. ${ }^{15}$

\begin{tabular}{|c|c|c|c|c|c|}
\hline Material & $\begin{array}{c}\text { Lethargy, } \\
\boldsymbol{5}\end{array}$ & $\begin{array}{c}\text { Macroscopic } \\
\text { Scattering Cross } \\
\text { Section }\left(\mathrm{cm}^{-1}\right), \Sigma \mathrm{s}\end{array}$ & $\begin{array}{c}\text { Macroscopic } \\
\text { Absorption } \\
\text { Cross Section } \\
\left(\mathrm{cm}^{-1}\right), \Sigma \mathrm{a}\end{array}$ & $\begin{array}{c}\text { Moderating } \\
\text { Power }\left(\mathrm{cm}^{-1}\right), \\
\boldsymbol{\Sigma} \mathbf{s}\end{array}$ & $\begin{array}{c}\text { Moderating } \\
\text { Ratio, } \zeta \\
\Sigma \mathrm{s} / \Sigma \mathrm{a}\end{array}$ \\
\hline Aluminum & 0.0723 & 0.084 & 0.015 & 0.006073 & 0.40488 \\
\hline Zirconium & 0.0218 & 0.338 & 0.008 & 0.007368 & 0.92105 \\
\hline
\end{tabular}

The parameters shown in Table 1 are used to qualitatively evaluate the impacts that changing the ATR fuel cladding from Al-6061 to $\mathrm{Zr}-4$ would have on the Reactor. As seen in Table 1, aluminum has a moderating ratio of 0.4 and zirconium has a larger moderating ratio of 0.9 , which indicates that zirconium is a more effective neutron moderator. The increased moderating power of zirconium indicates that neutrons are slowed down in fewer collisions than in aluminum. This is also evident in the lethargy parameters. Based on the parameters in Table 1, it can be assumed that given the same operating conditions, zirconium cladding would likely shift the neutron spectrum toward the thermal region. Also, the increased moderating ratio of zirconium would likely result in an increase in reactivity, due to the increased effectiveness of neutron moderation and a decrease in neutron absorptions.

The International Atomic Energy Agency (IAEA) Material Test Reactor (MTR) was studied to determine the results of changing the fuel cladding from aluminum to $\mathrm{Zr}-4$. The resulting simulations indicated that by changing only the fuel cladding material (maintaining a constant cladding thickness of $0.127 \mathrm{~cm}$ ) from aluminum to $\mathrm{Zr}-4$, there would be an increase in core excess reactivity $(\Delta \mathrm{k} / \mathrm{k})$ from 0.05411 to 0.017945 , a $59.9 \%$ increase in the thermal neutron flux, and an increase in the prompt neutron generation time from $44.03 \mu \mathrm{s}$ to $44.08 \mu \mathrm{s}$. Based on the properties described in Table 1 and the MTR simulations, there are no apparent disqualifying factors that would preclude $\mathrm{Zr}-4$ as being considered as a candidate cladding material, based on neutronic properties alone. A more detailed analysis is suggested to understand how a cladding change would impact the ATR.

\section{CONCLUSIONS and RECOMMENDATION}

In the event that aluminum becomes a nonviable option for the ATR fuel cladding, a more detailed analysis of the resulting thermal and structural changes associated with a change in fuel cladding should be performed. This assertion is predominantly based on the following:

- The density of $\mathrm{Zr}-4$ is $6.56 \mathrm{~g} / \mathrm{cm}^{3}$, which is significantly greater than the density of Al-6061, which is $2.715 \mathrm{~g} / \mathrm{cm}^{3}$. The volume of the fuel cladding plates in an ATR fuel element is $1,673.8$ $\mathrm{cm}^{3}$ and there are 40 fuel elements in the core; converting the aluminum fuel cladding plates to $\mathrm{Zr}-4$ would correspond to an increase in core mass of $257.4 \mathrm{~kg}$ in addition to the increases due to fuel meat changes. A structural analysis of the ATR fuel core is needed to evaluate the impact that a mass change of this magnitude would have on the core. 
Rev. 03

Title: $\quad$ Preliminary Investigation of Zircaloy-4 as a Research Reactor Cladding Material

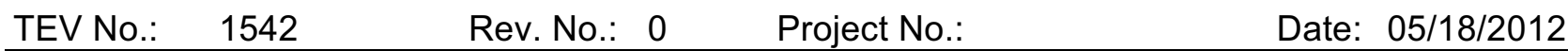

- As a first approximation, the oxidation rate of $\mathrm{Zr}-4$ should be much lower than aluminum in the ATR environment. Aluminum clad ATR fuel has a normal life of 45 effective full-power days, with a maximum cladding surface temperature of $181^{\circ} \mathrm{C}$. Zr-4 clad PWR fuel has a normal life of $\sim 1500$ effective full power days with a maximum cladding temperature of $360^{\circ} \mathrm{C}$. The commercial use of $\mathrm{Zr}-4$ indicates that it should be able to perform adequately in the ATR environment.

- The ATR coolant chemistry is maintained at $\mathrm{pH} 5.0$ to 5.4 with very low impurities to reduce the corrosion of the aluminum fuel cladding. EPRI recommends higher $\mathrm{pH}$ for commercial reactors using $\mathrm{Zr}-4$ cladding to reduce surface deposits, but $\mathrm{ZrO}_{2}$ is generally stable down to a $\mathrm{pH}$ of 2.0. The EPRI water chemistry guidance is considered to be overly conservative for the high purity and low temperature ATR coolant environment.

- The mechanical properties of $\mathrm{Zr}-4$ are superior to Al-6061. The HCP structure of $\mathrm{Zr}-4$ would require detailed fabrication process design to ensure fuel plate dimensional stability during irradiation.

- The thermal properties of $\mathrm{Zr}-4$ are significantly lower than Al-6061 and substantial requalification and analysis effort would be required to convert from Al-6061 cladding. Specifically, the thermal conductivity of $\mathrm{Zr}-4$ is significantly lower than Al-6061, which would result in a drastic decline in the heat removal from the fuel as the ATR is currently operated. A substantial change in heat removal from the fuel would likely result in higher fuel temperatures and non-beneficial changes in the operating parameters of the reactor.

- Zr-4 has lower thermal absorption cross-section than Al-6061 and has an increased scattering cross-section. Additional analysis will need to definitively determine the impact that these parameters would have on the ATR, but the identified trends associated with the cladding change are expected to cause increased reactivity and a shift in the neutron spectrum toward the thermal region. 
Rev. 03

Title: $\quad$ Preliminary Investigation of Zircaloy-4 as a Research Reactor Cladding Material

TEV No.: $1542 \quad$ Rev. No.: $0 \quad$ Project No.:

Date: $05 / 18 / 2012$

\section{REFERENCES}

1. PG-T-91-031, “Thermal and Mechanical Properties of ATR Core Materials,” August 1991.

2. IAEA-TEC-DOC-1496, "Thermophysical Properties Database of Materials for Light Water Reactors and Heavy Water Reactors," June 2006.

3. Oskarsson, M., et al, Oxidation of Zircaloy-2 and Zircaloy-4 in Water and Lithiated Water at $360^{\circ} \mathrm{C}$, Journal of Nuclear Material, Vol. 295, p. 97-108, 2001.

4. TRA-ATR-792, “ATR Fuel Element Oxide Thickness for UFSAR Analyses,” April 1992.

5. SAR 153, "Upgraded Final Safety Analysis Report for The Advanced Test Reactor," May 2012.

6. HEU-MET-THERM-022, “Advanced Test Reactor: Serpentine Arrangement of Highly Enriched Water-Moderated Uranium-Aluminide Fuel Plates Reflected by Beryllium,” October 2005.

7. ECAR 1006, “HEU-7F-YA Mass Difference and Center of Gravity,” August 2010.

8. TRA-ATR-1303, "Evaluation of ATR Fuel Element for Flow Blockage in Channel 20,"

9. PWR Primary Water Chemistry Guidelines, Vol. 1, Rev. 4, EPRI, TR-105714-V1R4, March 1999.

10. OMM-5.1.2.6.3, "Basis for ATR Water Systems Chemistry Limits,” June 2003.

11. TSR-186, “Technical Safety Requirements for the Advanced Test Reactor,”April 3, 2012.

12. ECAR-571, “ATR Primary Coolant System Filterable Solids Limits,” May 2009.

13. Lundberg, L., Croson, M., "Corrosion of Spent Advanced Test Reactor Fuel,” 1994.

14. Shoesmith, D., Zagidulin, D., The Corrosion of Zirconium Under Deep Geologic Repository Conditions, Journal of Nuclear Material, Vol. 418, p. 292-306, 2011.

15. Duderstadt, J., Hamilton, L., Nuclear Reactor Analysis, John Wiley \& Sons, Inc.

16. STUK-YTO-TR 173, "Spent Fuel Verification Options for Final Repository Safeguards in Finland," December 2000.

17. TRA-ATR-1240, “Partial Structural Evaluation of ATR Fuel Elements,” July 1997.

19. TEM-10200-1, "RERTR Full-Size Element Assembly Structural Evaluation for ATR Vessel Loadings," March 2012. 
Rev. 03

Title: $\quad$ Preliminary Investigation of Zircaloy-4 as a Research Reactor Cladding Material

TEV No.: $1542 \quad$ Rev. No.: $0 \quad$ Project No.:

Date: $05 / 18 / 2012$

20. BNWL-1820, "Feasibility Studies for Decontamination and Densification of Chop-Leach Cladding Residues, July 1974.

21. Corrosion Resistance of Zirconium, from Article: Corrosion of Zirconium and Hafnium, ASM Metals Handbook, Volume 13, Nov 2001

22. Was, G.S., Busby, J., and Andresen, P. L., Effect of Irradiation on Stress-Corrosion Cracking and Corrosion in Light Water Reactors, Metalworking; Bulk Forming, Vol. 13C, ASM Handbook, ASM International, 2006, P386 - 414. 